\title{
Resection of retrocrural germ cell tumor metastases: Two surgical approaches
}

\author{
Stefan Sponholz, MD, Stephan Trainer, MD, Moritz Schirren, MD, and Joachim Schirren, MD
}

\section{ABSTRACT}

Objectives: The goals of retrocrural metastasectomy are complete resection with preservation of the diaphragmatic function while avoiding phrenic nerve injury and spinal cord ischemia. We describe 2 approaches for metastasectomy depending on the pattern of metastases.

Methods: Between 1999 and 2017, 44 patients underwent 50 retrocrural metastasectomies. In case of lower retrocrural, bilateral retrocrural, and or additional retroperitoneal and abdominal metastases, an abdominal approach with mobilization of the liver and the kidney followed by longitudinal incision of the diaphragmatic crus was performed. In case of upper retrocrural metastases and additional thoracic disease, a thoracic approach was performed. The Kaplan-Meier method and log-rank test were used to analyze survival and prognosticators.

Results: The minor morbidity, major morbidity, and mortality were $16.6 \%, 0 \%$, and $0 \%$ for the abdominal approach, respectively, and $15.4 \%, 3.8 \%$, and $0 \%$ for the thoracic approach. There was no phrenic nerve palsy, diaphragmatic hernia, or spinal cord ischemia. Additional retroperitoneal, mediastinal, pulmonary, or further resection was necessary in 10, 25, 9, and 6 cases, respectively. In all cases, a $\mathrm{R} 0$ resection was achieved. The 15 -year survival rate was $95 \%$.

Conclusions: Depending on the pattern of metastases, a complete retrocrural metastasectomy with low morbidity and without mortality by thoracic or abdominal approach is possible. Both approaches preserve diaphragmatic function. Furthermore, the lateral abdominal approach provides a good view and might lead to less tension at the spinal arteries and therefore might reduce the risk of paresis. Good long-term survival is achievable. These patients should be operated on in specialized centers. (J Thorac Cardiovasc Surg 2019;157:2482-9)

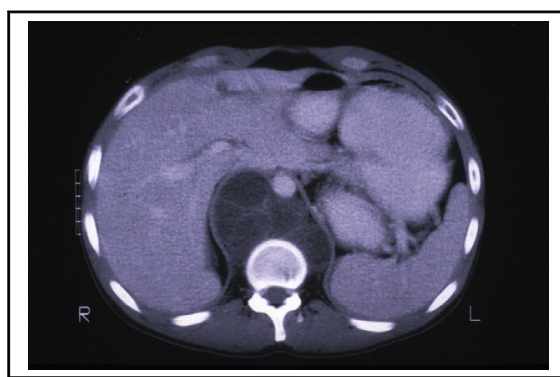

Computed tomography image showing retrocrural germ cell tumor metastases.

\section{Central Message}

Depending on the pattern of metastases, a complete retrocrural metastasectomy with low morbidity and good long-term outcome is possible by thoracic or abdominal approach

\section{Perspective}

This study analyzed and describes 2 surgical approaches to resect retrocrural germ cell cancer metastases, mostly with additional metastases. In all cases a R0 resection was achieved and a phrenic nerve injury and spinal cord ischemia could be avoided.

See Commentary on page 2490 .
Cisplatin-based chemotherapy regimens are typically the therapies of choice for germ cell cancer and result in good long-term and disease-free survival rates. ${ }^{1,2}$ Neither a decrease in tumor markers nor imaging methods allows for histologic differentiation of the residual tumors. Therefore, the consensus in the literature is to resect the residual disease. ${ }^{3-7}$

From the Department of Thoracic Surgery, Agaplesion Markus Krankenhaus, Frankfurt, Germany.

Read at The American Association for Thoracic Surgery Thoracic Summit, New York, New York, October 12-13, 2018.

This work is part of a doctoral thesis prepared by Stephan Trainer, MD.

Received for publication Sept 26, 2018; revisions received Jan 17, 2019; accepted for publication Jan 22, 2019; available ahead of print March 14, 2019

Address for reprints: Stefan Sponholz, MD, Department of Thoracic Surgery, Agaplesion Markus Krankenhaus, Wilhelm-Epstein-Str 4, 60431 Frankfurt, Germany (E-mail: stefan.sponholz@fdk.info).

$0022-5223 / \$ 36.00$

Copyright (c) 2019 by The American Association for Thoracic Surgery

https://doi.org/10.1016/j.jtcvs.2019.01.119
The retrocrural space is a specific location where germ cell cancer metastases may occur. The thoracic duct provides the metastatic pathway, which can extend up to the supraclavicular space (Figure 1). The ventral and lateral borders are the diaphragmatic crura. Posteriorly, the space reaches to the vertebral bodies, including the aorta with intercostal and spinal arteries, azygos and hemiazygos veins, lymphatic structures such as the thoracic duct, and nerves. 8,9

The resection of retrocrural metastases is very challenging. ${ }^{7,10-12}$ The reported complications of retrocrural metastasectomy include injuries to nearby organs and vessels, chyle leakage, diaphragmatic paralysis, and pneumonia. In addition, paresis or paraplegia may occur

To view the AATS Webcast, see the URL next to the webcast thumbnail. 


\section{Abbreviations and Acronyms \\ $\mathrm{CT}=$ computed tomography \\ ICS $=$ intercostal space}

due to injury to intercostal arteries with their spinal branches. ${ }^{7,10,12-15}$ Different surgical approaches to resect retrocrural metastases and additional metasases have been described.

Nevertheless, the goals of metastasectomy are complete resection with low morbidity and mortality. In our institution, we used 2 different approaches to reach the retrocrural space depending on the locations of the metastases and the existence of additional metastases. This study describes the 2 approaches and analyzes the completeness of resection, morbidity, and mortality. Furthermore, long-term survival and the potential prognostic factors for survival were investigated.

\section{METHODS}

This retrospective analysis was performed using a prospectively maintained database. The institutional review board approved the study, which was conducted according to the revised Declaration of Helsinki and the requirements of good clinical practice.

This study included 44 patients who underwent retrocrural resection for germ cell cancer at our institution from 1999 to 2017. All patients received previous chemotherapy and resection of the primary tumor. Oncologic staging was performed that included tumor markers, bone scans, magnetic resonance imaging of the brain and chest, and abdominal and pelvic computed tomography (CT). Furthermore, all patients received lung and cardiac function tests. Postoperative morbidity was classified according to minor and major morbidity using the TM\&M classification system of Ottawa Hospital. ${ }^{16}$

The preoperative and postoperative data were prospectively documented. The follow-up data were collected out of clinical data, telephone interviews, and correspondence with the attending physicians. Patients were monitored with tumor markers and chest CT 2 to 3 months after metastasectomy and later in longer intervals.

In addition to morbidity and mortality, the radicality of the surgical approach and overall survival, calculated from the time of retrocrural resection, were also analyzed. Phrenic nerve palsy, diaphragmatic paresis, or hernia were evaluated by postoperative chest radiograph and follow-up CT. Long-term outcomes and survival curves were performed using the Kaplan-Meier method. Prognosticators and survival differences were calculated by log-rank test. All analyses were performed using SPSS 22.0 software (IBM-SPSS Inc, Armonk, NY).

\section{Surgical Approaches}

The abdominal approach was routinely performed in collaboration with a urologist. In this approach, a patient is positioned in a hyperextended back position and intubated with a double-lumen endobronchial tube. A bilateral transverse upper abdominal laparotomy is performed. The ligamentum falciforme, triangulare, and coronaria are cut so that the liver is mobilized (Figure 2, A). The incision is extended around the right kidney without cutting the ligamentum hepato-renale. Next, the liver and kidney are mobilized medially (Figure 2, B). At this point, it is important to pay attention to the veins of the liver and renal hilum. The diaphragm and diaphragmatic crura are now accessible, which is cut by a longitudinal incision. The phrenic nerve branches at the top of the diaphragm and, due to the ventral approach, phrenic nerve palsy can be avoided. This approach offers an excellent view of the retrocrural space (Figure 2, $C$ and $D$ ). Depending on the constitution of the patient, a dissection can be performed up to the subcarinal space. The metastases can be resected and lymph vessels, veins, and arteries can be ligated. It is very important to give care to the spinal cord arteries to avoid an ischemia. A provocation test with cream to determine whether the thoracic duct is injured can be performed through a nasogastric tube.

In cases with left-sided metastases or bilateral disease, mobilization of the spleen, the left colonic flexure, and the kidney to medial can be performed in the same way. After resection of the metastases, a drainage tube is placed and the diaphragmatic crus are closed by a continuous suture. The mobilized organs can be put back into position without fixation.

In patients with additional retroperitoneal or abdominal (eg, liver) metastases, an additional resection can be performed. Altogether, using this approach, lower retrocrural, bilateral retrocrural, additional retroperitoneal, or abdominal metastases can be resected. If necessary, this approach also allows extended resections as a vertebral body resection (Table 1).
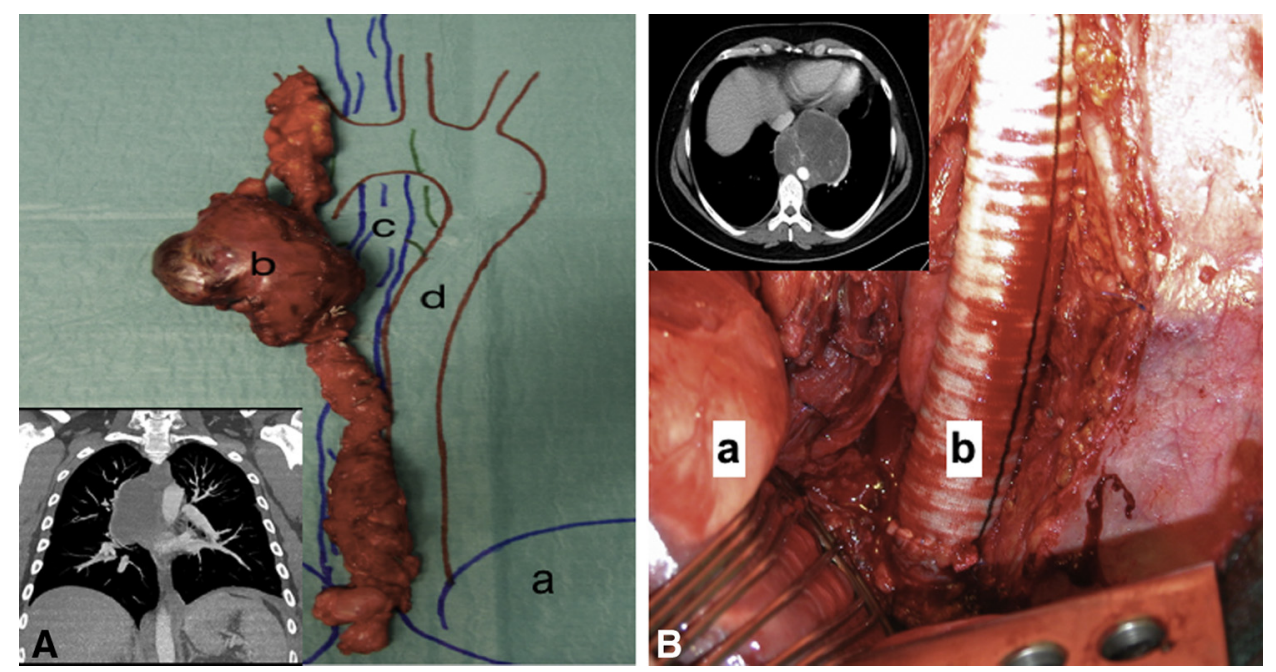

FIGURE 1. A, Computed tomography (CT) scan and via thoracic approach en bloc resected teratoma growing along the lymphatic duct ( $a$, diaphragm; $b$, tumor; $c$, esophagus; $d$, aorta). B, CT scan and intraoperative aortic replacement after resection of an aorta infiltrating rhabdomyosarcoma ( $a$, diaphragm; $b$, aortic prosthesis). 

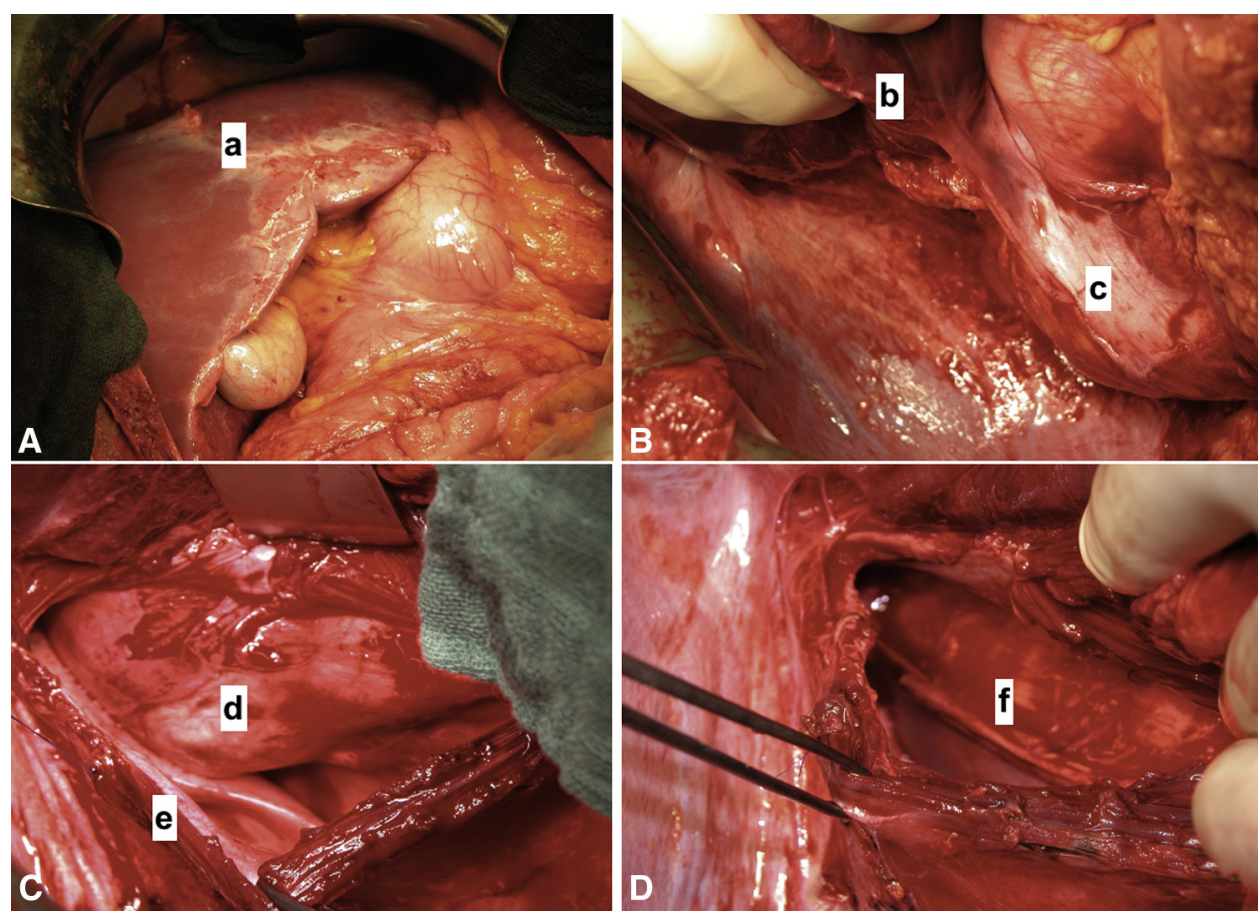

FIGURE 2. Abdominal approach. A and B, After cutting the liver ligaments $(a)$, the liver $(b)$ and the kidney $(c)$ are mobilized medially to reach the diagphragmatic crus. C, The retrocrural metastasis $(d)$ is reached by a longitudinal incision of the diaphragmatic crus $(e)$. D, Retrocrural space after tumor resection $(f$, vertebra).

In patients with upper retrocrural metastases and additional thoracic disease (mediastinal and/or pulmonary), a skin incision, such as that in a usual posterolateral thoracotomy, is performed (thoracic approach). After cutting the muscles, 2 thoracotomies are performed to enter between the intercostal spaces (ICSs) (fifth ICS and either eighth or ninth ICS). In some cases, a lower posterolateral thoracotomy is enough and a skin incision is performed in accordance with the planned thoracotomy (eighth or ninth ICS).

To reach the retrocrural space, mobilization of the esophagus is often needed (Figure 3, A). On the right side, the assistant can carefully pull the liver aside with a hook. It is important to pay attention to the azygos vein and branchial arteries of the aorta, which may cause major bleeding. Additionally, a provocation test can be performed to determine whether the thoracic duct is injured.

In patients with left-sided metastases, one must take care to not injure the spleen while holding the diaphragm aside with a hook. In summary, using this approach, metastases of the upper-retrocrural space can be resected and sometimes combined with resection of mediastinal metastases, supraaortic or lung metastases, or extended resections as an aortic replacement (Figure 1 and Figure 3, $B$ ).

\section{RESULTS}

\section{Patient Demographic and Clinical Characteristics}

Out of all our patients with germ cell cancer metastases treated between 1999 and 2017 in our institution, only 44 patients $(8.1 \%)$ were operated on for retrocrural metastases using these approaches.

The median patient age was 32 years (range, $18-53$ years). The median follow-up time as measured from the first metastasectomy was 93 months (range, 12-227 months). The primary tumor occurred most frequently in the testis $(93.2 \%$; $\mathrm{n}=41)$, and $6.8 \%(\mathrm{n}=3)$ had extragonadal germ cell cancer. All patients received chemotherapy, with most receiving a combination of platin, etoposide, and bleomycin $(68 \% ; n=30)$. Eight patients received additional high-dose chemotherapy, and 6 patients underwent stem cell transplantation. The predominant histology was nonseminomateous germ cell cancer, which accounted for $86.3 \%$ of patients, 5 patients had a teratoma $(11.4 \%)$, and 1 patient had a seminoma as the primary tumor $(2.3 \%)$. Table 1 shows the distribution of retrocrural metastases and the number of additional metastases.

\section{Operative and Histologic Data}

In total, 50 operations were performed to resect retrocrural germ cell tumors and 3 patients experienced recurrent metastases. Regarding the surgical technique employed to remove the metastatic tumors, $48 \%$ were resected using the transabdominal approach $(\mathrm{n}=24)$, whereas $52 \%$ underwent resection using the transthoracic approach $(n=26)$. The combination of a transverse upper laparotomy and thoracotomy was performed twice. For classification of the postoperative data, these patients were included in the laparotomy group.

Most of the resections were a combination of retrocrural metastasectomy and a resection of additional metastases (eg, mediastinal). Only 4 metastasectomies were performed in which the patient only demonstrated retrocrural 
TABLE 1. Distribution of the retrocrural tumor, additional metastases, and extended resections $(N=44)$

\begin{tabular}{lc}
\hline \multicolumn{1}{c}{ Outcome } & $\mathbf{n}(\%)$ \\
\hline Retrocrural tumor burden & \\
Unilateral & $32(72.7)$ \\
Bilateral & $12(27.3)$ \\
Retroperitoneal metastases & \\
Yes & $44(100)$ \\
No & $0(0)$ \\
Mediastinal metastases & \\
Yes & $40(90.9)$ \\
No & $4(9.1)$ \\
Lung metastases & \\
Yes & $21(47.7)$ \\
No & $23(52.3)$ \\
Supraclavicular metastases & \\
Yes & $18(40.9)$ \\
No & $26(59.1)$ \\
Liver metastases & \\
Yes & $2(4.5)$ \\
No & $42(95.5)$ \\
Extended resection $(\mathrm{n}=6 *)$ & Histology \\
Vertebral body & Necrosis and teratoma \\
Aorta & Rhabdomyosarcoma \\
Liver & Teratoma \\
Kidney & Teratoma \\
Adrenal gland & Teratoma \\
Diaphragm & Teratoma \\
\hline
\end{tabular}

*There was 1 instance of each extended resection.

metastases. In these 4 cases, the abdominal surgical approach was employed. The most prevalent locations for the occurrence of additional tumors included the mediastinum $(\mathrm{n}=25)$, retroperitoneum $(\mathrm{n}=10)$, and lung $(\mathrm{n}=9)$. In 6 patients, an extended resection (eg, organs, aorta, or vertebral body) was performed (Table 1). If a retroperitoneal resection was necessary, it was performed by a urologic surgeon. In case of previous retroperitoneal resection, the median time between retroperitoneal resection and our operation was 6 months (range, 0-266 months).

Regarding postoperative histology, $81.8 \%$ of tumors were mature teratomas, $6.9 \%$ showed necrosis, $4.5 \%$ were yolk sac tumors, $4.5 \%$ exhibited viable cancer cells, and $2.3 \%$ were rhabdomyosarcomas. In all cases, a R0 resection was achieved.

\section{Morbidity and Mortality}

For the abdominal approach, the minor and major morbidities were $16.6 \%$ and $0 \%$, respectively, with no 30-day or 90-day mortality. For the thoracic approach, the minor and major morbidities were $15.4 \%$ and $3.8 \%$, respectively, again with no 30-day or 90-day mortality.

The most critical morbidity that was observed using the abdominal approach was chyle leakage that persisted for 7 days due to a diet that included medium-chain triglycerides. Regarding the thoracic approach, the most critical morbidity was a hemothorax that resulted from bleeding of an intercostal artery. Table 2 displays the morbidities related to the approaches. Altogether, none of the 50 operations resulted in phrenic nerve palsy, diaphragmatic hernia, or spinal cord ischemia.

\section{Survival, Recurrent Disease, and Survival Prognosticators}

One patient was lost to follow-up after 4 months and was therefore not included in the survival analyses. Altogether, 43 patients were included in the long-term follow-up. The $5-, 10-$, and 15 -year survival rates were $95 \%, 95 \%$, and $95 \%$, respectively (Figure 4). Furthermore, 38 patients were included in the recurrence rate analyses. Of these patients, 5 had recurrent retrocrural metastases, and 4 of 5 patients underwent a second operation, whereas 1 patient underwent experimental cryoablation therapy.

Regarding the prognosticators for survival, patient age $(P=.794)$, the disease-free time interval between the

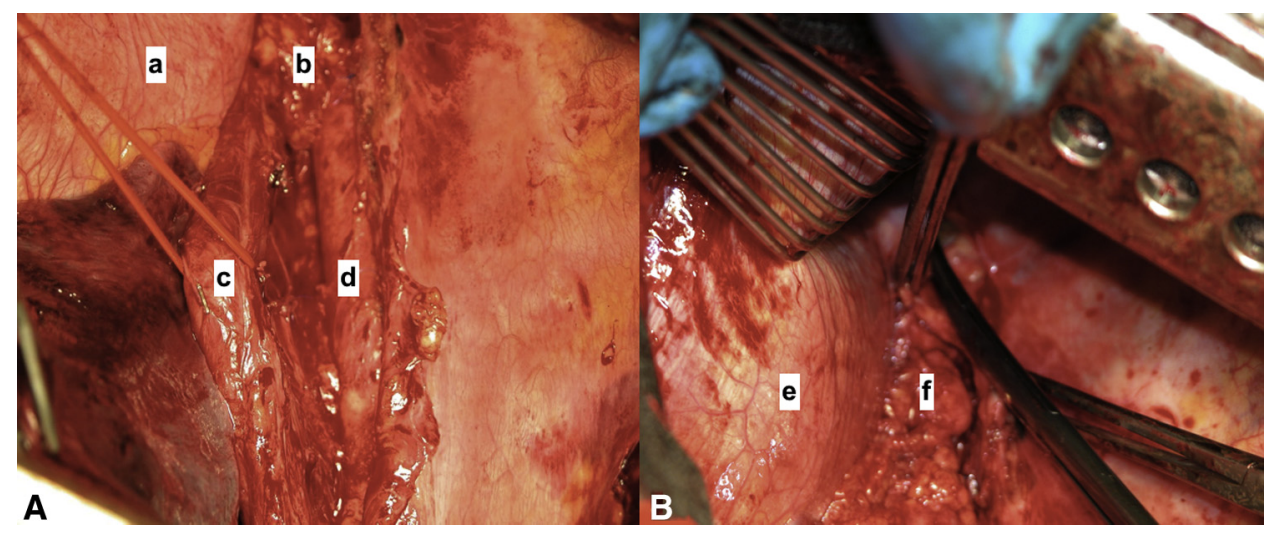

FIGURE 3. Thoracic approach. A, Mobilization of the esophagus ( $a$, diaphragm; $b$, tumor; $c$, esophagus; $d$, aorta). B, View of the thoracic approach to the tumor burden ( $e$, diaphragm; $f$, tumor). 
TABLE 2. Postoperative morbidity and mortality related to the approach

\begin{tabular}{ccll}
\hline Approach & Instance (\%) & Morbidity & No. \\
\hline Abdominal ( $\mathrm{n}=24)$ & & & \\
Minor morbidity & 16.6 & Chyle leakage & 1 \\
Major morbidity & 0 & Pneumonia & 1 \\
30-d mortality & 0 & Anemia & 1 \\
90-d mortality & 0 & Wound infection & 1 \\
Thoracic (n = 26) & & & \\
Minor morbidity & 15.4 & Hemothorax & 1 \\
Major morbidity & 3.8 & Pneumonia & 2 \\
30-d mortality & 0 & Anemia & 1 \\
90-d mortality & 0 & Wound infection & 1 \\
\hline
\end{tabular}

primary cancer and metastasis $(P=.204)$, additional lung $(P=.151)$ or supraclavicular metastases $(P=.279)$, and the type of surgical approach $(P=.201)$ had no influence on survival.

\section{DISCUSSION}

Retroperitoneal and thoracic metastases of germ cell cancer can occur due to lymphogenous and/or hematogenous spread. Retrocrural and mediastinal metastases may grow along the thoracic duct and are mostly associated with a high tumor burden. ${ }^{10,11}$ All of our patients had additional metastases, most commonly in the retroperitoneum or mediastinum (Table 1). As a result, most patients require several operations to achieve complete remission. ${ }^{7,17}$ Different surgical approaches have been described in the literature that enable the resection of all metastases in one procedure. ${ }^{13,17}$ Indeed, significant efforts have been made toward reaching different metastatic locations in 1 surgical approach. ${ }^{7,11,14,15}$ Here, it is important not to risk the long-term survival of the patient by performing a $\mathrm{R} 1$ or R2 resection. ${ }^{10,18}$ Germ cell cancer metastases

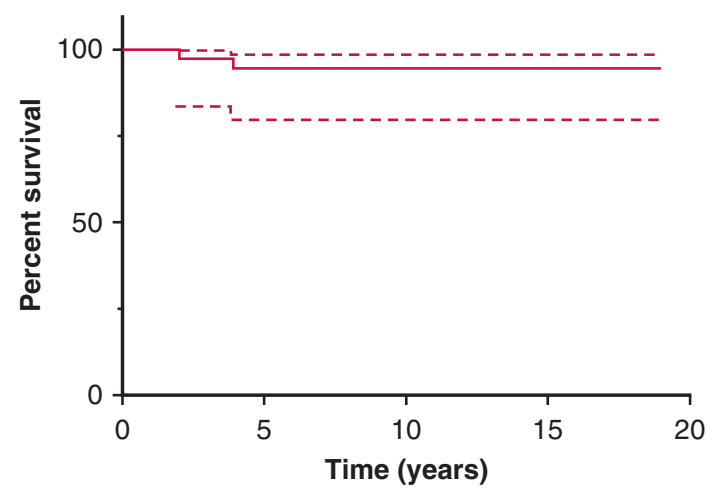

\begin{tabular}{lcccc}
\hline Years & $\mathbf{0}$ & $\mathbf{5}$ & $\mathbf{1 0}$ & $\mathbf{1 5}$ \\
\hline Patients at risk & 43 & 30 & 17 & 6 \\
\hline
\end{tabular}

FIGURE 4. Overall survival and 5-, 10-, and 15-year survival. sometimes have a cystic structure, and it is sometimes difficult to resect the cystic components after tumor opening. However, a complete R0 resection is necessary to avoid recurrence (Figure 5). Clearly, the choice of surgical approach for these metastasectomies is critical. In all cases included in this study, we performed an en bloc R0 resection due to the differences between the 2 surgical approaches that result from the different tumor locations (Figure 1).

Other important aspects of the operation include the morbidity and mortality rates in this challenging surgery. ${ }^{7,10,11}$ However, the morbidity and mortality rates in this study were low, which is consistent with previous literature reports. ${ }^{7,11,14,15}$ Possible complications after retrocrural metastasectomy are injuries to certain organs and vessels, chyle leakage, phrenic nerve palsy, pneumonia, and paresis or paraplegia. ${ }^{7,10,13-15,19}$ In our study, none of the 50 operations resulted in phrenic nerve palsy, diaphragmatic hernia or spinal cord ischemia (Table 2). Among the most feared complications from this type of surgery is spinal cord ischemia. ${ }^{12,14,19}$ If anatomically and oncologically feasible, an attempt is made to spare largerdiameter intercostal arteries. ${ }^{14}$ Our lateral abdominal approach with mobilization of the liver or spleen provided a good view for this attempt. Furthermore, because the spinal arteries arise posterolaterally from the aorta, the lateral approach may result in less tension at the spinal arteries than a more direct surgical approach that goes between the aorta and the inferior vena cava. Thus, this surgical approach might reduce the risk of paresis; however, it is very important to spare as much of the intercostal and spinal arteries as oncologically feasible.

In 1997, Christmas and colleagues ${ }^{11}$ described 14 resections using an extraperitoneal thoracoabdominal approach with incision of the eighth rib, paramedian incision, excision of the anterior rib portion, and splitting of the diaphragm. They described a good view of the retrocrural space and, due to the extraperitoneal approach, postoperative ileus could be prevented. In our opinion, the incision of the diaphragm and the risk of diaphragm paresis is a disadvantage of this approach because it may lead to decreased lung capacity, decreased cough, and an increased risk of lower lobe atelectasis or pneumonia. Given that almost $50 \%$ of patients in this study had additional lung metastases, preservation of the lung and diaphragmatic functions is essential. Furthermore, incision and excision of the rib and anterior rib portion might lead to healing disorders because it is bradytrophic, less vascularized tissue. Fadel and colleagues ${ }^{15}$ criticized the 1 -sided thoracoabdominal approach to the mediastinum and thorax because of the inferior view of the aorta. We also see this as a critical point because $25 \%$ of our patients had bilateral retrocrural metastases. Some other centers use a further unilateral extrapleural-retroperitoneal approach to expose the 


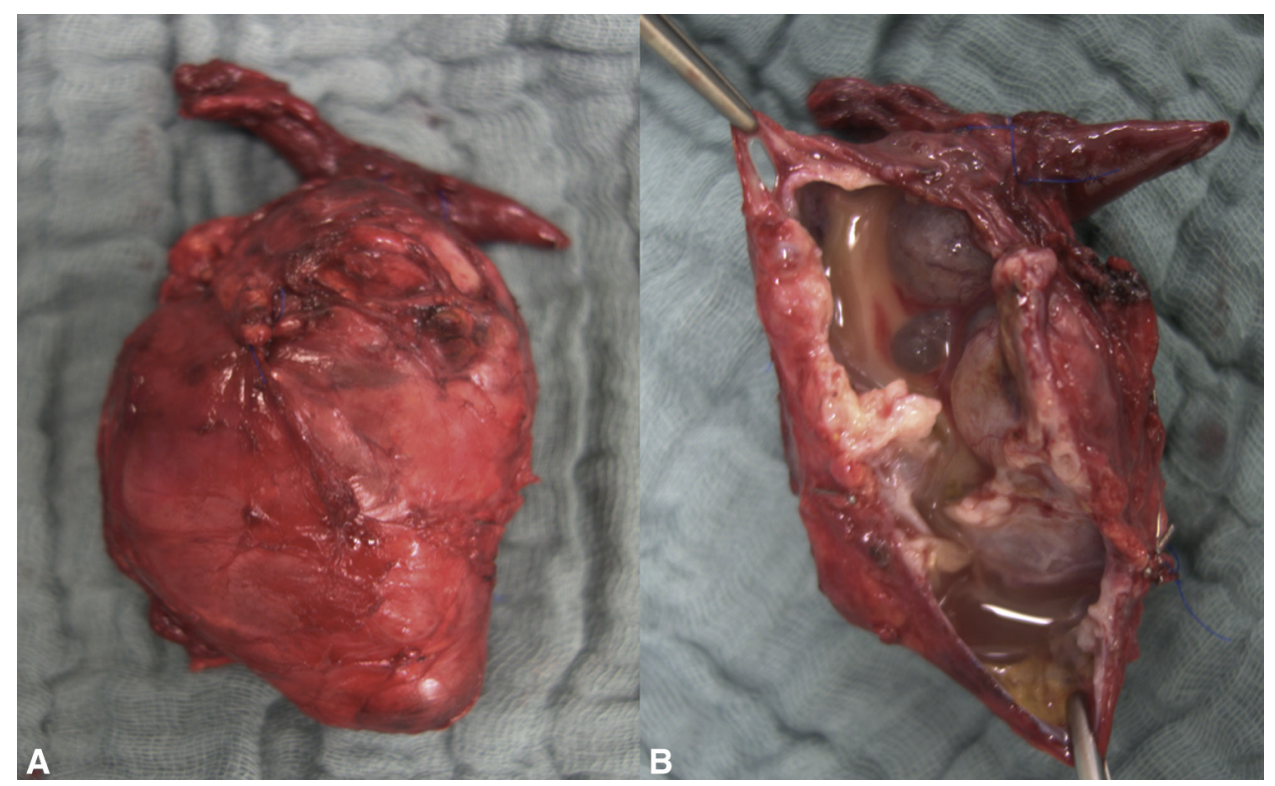

FIGURE 5. Germ cell tumor metastasis. A, R0 resection of retrocrural cystic tumor. B, Cystic tumor (opened after extirpation).

thoracolumbar junction, which reduces the risk of respiratory morbidity. ${ }^{20,21}$ This approach might be a good option in isolated, unilateral retrocrural metastases, especially after previous retroperitoneal metastasectomy. However, in our study only 2 patients had unilateral isolated retrocrural disease.

All patients in this study had retroperitoneal metastases, and most of these metastases were resected in another hospital before this study. Altogether, only 10 patients were referred to us for a combined resection of retrocrural and retroperitoneal metastases, which shows that the combined resection is not very popular; thus, patients with metastases in different areas should be treated in specialized centers. Fadel and colleagues ${ }^{15}$ described 18 patients who received midline laparotomy for a combined resection of retrocrural and retroperitoneal metastases. The advantages of the combined resection are a shorter length of hospital stay and, if necessary, an earlier opportunity for adjuvant chemotherapy. Altogether, the morbidity is comparable to our study. ${ }^{15}$ Like Fadel and colleagues, ${ }^{15}$ we used a longitudinal incision of the diaphragmatic crus to preserve the lung and diaphragmatic functions (Figure 2). As mentioned above, we believe the direct approach that goes between the aorta and inferior vena cava may provide an inferior view of the intercostal and spinal arteries and, furthermore, may increase the tension to the arteries. For these reasons, we prefer a lateral approach to the retrocrural space. By this approach we also resected additional organ metastases or infiltrating tumors from 6 patients. To achieve a complete resection in 1 patient a verterbral body resection was necessary and in another patient a resection of the aorta descendens was necessary (Table 1). Extended resections like resections of the aorta are rare because usually the metastases are not infiltrating the adventitia, but in some cases especially in malignant transformation or persisting germ cell cancer an extended resection is needed. However, despite the extended resections, there was no morbidity or mortality. This was also the case for patients who required reoperation due to recurrent disease. These results show that extended resections can be performed using these approaches with promising results.

Clearly, the thoracic approach has several advantages when combining resection of upper retrocrural metastases and mediastinal and/or lung metastases. Furthermore, the resection may be extended along the thoracic duct to the supra-aortic vessels (Figure 1). The view of the lung hilum is very good and facilitates the resection of lung and mediastinal metastases. In this study, we achieved a R0 resection for all retrocrural metastases using this approach. A proficient surgeon can decide whether the retrocrural metastases are resectable using the thoracic approach via computed tomography.

Studies of patients with lung and mediastinal metastases showed 5- and 10-year survival rates of $79 \%$ to $87 \%$ and $73 \%$ to $85 \%$, respectively. ${ }^{7,22-24}$ The median follow-up time in this study was 93 months (range, 12-227 months). The 5-, 10- and 15-year survival rates in this study were all $95 \%$. The most important prognosticator for good long-term survival is complete tumor resection. ${ }^{3,7,23-25}$ For this reason, residual tumors after chemotherapy should be resected in specialized centers. In addition to incomplete resection, tumor histology and increased 
patient age have been described as negative prognosticators for survival. ${ }^{3,7,22-25}$ However, patient age had no influence in this study. Furthermore, the disease-free time interval between the primary cancer and metastasis, additional lung or supraclavicular metastases, and type of surgical approach did not negatively influence survival.

Cary and colleague ${ }^{26}$ found in three-fourth of their patients teratoma or viable cancer, this demonstrates the importance of retroperitoneal tumor resection after highdose chemotherapy and stem cell transplantation. In our study $93.1 \%$ of patients had teratoma or viable cancer, and only $6.9 \%$ necrosis, in the postoperative histology. This and the good long-term survival underlines the importance to operate these patients even in case of high tumor burden.

We cannot report how many spinal arteries had been resected during dissection which, depending on patients' anatomy, ${ }^{27}$ might have an influence on postoperative paresis. This is a limitation of the study. Regarding the survival analyses, the study population did not allow us to evaluate the influence of the residual pathology or of the serum markers.

\section{CONCLUSIONS}

Altogether, depending on the pattern of metastases, a complete retrocrural metastasectomy with low morbidity and without mortality by thoracic or abdominal approach is possible. Both approaches preserve the phrenic nerve and diaphragmatic function. Furthermore, the lateral abdominal approach provides a good view and leads to less tension at the spinal arteries and therefore might reduce the risk of paresis and bleeding. Good long-term survival is achievable, and we recommend that these patients undergo surgery at specialized centers.

\section{Webcast}

You can watch a Webcast of this AATS meeting presentation by going to: https://aats.blob.core.windows.net/ media/ITSOS18/GS-13-1315-1330-Sponholz-720p.mp4.

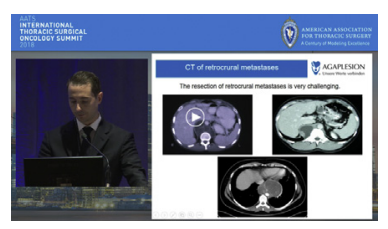

\section{Conflict of Interest Statement}

Authors have nothing to disclose with regard to commercial support.

\section{References}

1. Einhorn LH. Treatment of testicular cancer: a new and improved model. J Clin Oncol. 1990;8:1777-81.

2. Hinton S, Catalano PJ, Einhorn LH, Nichols CR, David Crawford E, Vogelzang N, et al. Cisplatin, etoposide and either bleomycin or ifosfamide in the treatment of disseminated germ cell tumors: final analysis of an intergroup trial. Cancer. 2003;97:1869-75.

3. Fizazi K, Tjulandin S, Salvioni R, Germà-Lluch JR, Bouzy J, Ragan D, et al. Viable malignant cells after primary chemotherapy for disseminated nonseminomatous germ cell tumors: prognostic factors and role of postsurgery chemotherapy-results from an international study group. J Clin Oncol. 2001;19: 2647-57.

4. Fizazi K, Oldenburg J, Dunant A, Chen I, Salvioni R, Hartmann JT, et al. Assessing prognosis and optimizing treatment in patients with postchemotherapy viable nonseminomatous germ-cell tumors (NSGCT): results of the sCR2 international study. Ann Oncol. 2008;19:259-64.

5. Schmoll HJ, Souchon R, Krege S, Albers P, Beyer J, Kollmannsberger C, et al. European consensus on diagnosis and treatment of germ cell cancer: a report of the European Germ Cell Cancer Consensus Group (EGCCCG). Ann Oncol. 2004; 15:1377-99.

6. Sonneveld DJ, Sleijfer DT, Koops HS, Keemers-Gels ME, Molenaar WM, Hoekstra HJ. Mature teratoma identified after postchemotherapy surgery in patients with disseminated nonseminomatous testicular germ cell tumors: a plea for an aggressive surgical approach. Cancer. 1998;82:1343-51.

7. Kesler KA, Kruter LE, Perkins SM, Rieger KM, Sullivan KJ, Runyan ML, et al. Survival after resection for metastatic testicular nonseminomatous germ cell cancer to the lung or mediastinum. Ann Thorac Surg. 2011;91:1085-93.

8. Restrepo CS, Eraso A, Ocazionez D, Lemos J, Martinez S, Lemos DF. The diaphragmatic crura and retrocrural space: normal imaging appearance, variants, and pathologic conditions. Radiographics. 2008;28:1289-305.

9. Trainer S, Bergmann T, Bölükbas S, Weissbach L, Figge M, Schirren J. [The approach to tumors of the retrocrural mediastinum]. Chirurg. 2008;79:26-9.

10. Hejase MJ, Donohue JP, Foster RS, Bihrle R, Coogan CL, Rowland R, et al. Postchemotherapy resection of nonseminomatous germ cell testicular tumors metastatic to the mediastinum. J Urol. 1996;156:1345-8.

11. Christmas TJ. Retrocrural lymph node metastases from testis germ cell tumours: removal via a thoraco-abdominal extraperitoneal approach after chemotherapy. Br J Urol. 1997;79:468-70.

12. Kesler KA. Surgical techniques for testicular nonseminomatous germ cell tumors metastatic to the mediastinum. Chest Surg Clin N Am. 2002;12:749-68.

13. Tognoni PG, Foster RS, McGraw P, Heilman D, Bihrle R, Rowland RG, et al. Combined post-chemotherapy retroperitoneal lymph node dissection and resection of chest tumor under the same anesthetic is appropriate based on morbidity and tumor pathology. J Urol. 1998;159:1833-5.

14. Kesler KA, Brooks JA, Rieger KM, Fineberg NS, Einhorn LH, Brown JW. Mediastinal metastases from testicular nonseminomatous germ cell tumors: patterns of dissemination and predictors of long-term survival with surgery. J Thorac Cardiovasc Surg. 2003;125:913-23.

15. Fadel E, Court B, Chapelier AR, Droz JP, Dartevelle P. One-stage approach for retroperitoneal and mediastinal metastatic testicular tumor resection. Ann Thorac Surg. 2000;69:1717-21.

16. Seely AJ, Ivanovic J, Threader J, Al-Hussaini A, Al-Shehab D, Ramsay T, et al. Systematic classification of morbidity and mortality after thoracic surgery. Ann Thorac Surg. 2010;90:936-42.

17. Brenner PC, Herr HW, Morse MJ, Sheinfeld J, Aprikian A, Bosl GJ, et al. Simultaneous retroperitoneal, thoracic, and cervical resection of postchemotherapy residual masses in patients with metastatic nonseminomatous germ cell tumors of the testis. J Clin Oncol. 1996;14:1765-9.

18. Anyanwu E, Krysa S, Buelzebruck H, Vogt-Moykopf I. Pulmonary metastasectomy as secondary treatment for testicular tumors. Ann Thorac Surg. 1994;57: 1222-8.

19. Leibovitch I, Nash PA, Little JS Jr, Foster RS, Donohue JP. Spinal cord ischemia after post-chemotherapy retroperitoneal lymph node dissection for nonseminomatous germ cell cancer. J Urol. 1996;155:947-51.

20. Barone GW, Eidt JF, Webb JW, Hudec WA, Pait TG. The anterior extrapleural approach to the thoracolumbar junction revisited. Am Surg. 1998;64:372-5.

21. Kim M, Nolan P, Finkelstein JA. Evaluation of 11 th rib extrapleuralretroperitoneal approach to the thoracolumbar junction. Technical note. J Neurosurg. 2000;93(1 Suppl):168-74. 
22. Liu D, Abolhoda A, Burt ME, Martini N, Bains MS, Downey RJ, et al. Pulmonary metastasectomy for testicular germ cell tumors: a 28-year experience. Ann Thorac Surg. 1998;66:1709-14.

23. Schirren J, Trainer S, Eberlein M, Lorch A, Beyer J, Bölükbas S. The role of residual tumor resection in the management of nonseminomatous germ cell cancer of testicular origin. J Thorac Cardiovasc Surg. 2012;60:405-12.

24. Cagini L, Nicholson AG, Horwich A, Goldstraw P, Pastorino U. Thoracic metastasectomy for germ cell tumours: long term survival and prognostic factors. Ann Oncol. 1998;9:1185-91.

25. Pfannschmidt J, Hoffmann H, Dienemann H. Thoracic metastasectomy for nonseminomatous germ cell tumors. J Thorac Oncol. 2010;5(6 Suppl 2): S182-6.
26. Cary C, Pedrosa JA, Jacob J, Beck SD, Rice KR, Einhorn LH, et al. Outcomes of postchemotherapy retroperitoneal lymph node dissection following high-dose chemotherapy with stem cell transplantation. Cancer. 2015;121: 4369-75.

27. Kari FA, Saravi B, Krause S, Puttfarcken L, Scheumann J, Förster K, et al. New insights into spinal cord ischaemia after thoracic aortic procedures: the importance of the number of anterior radiculomedullary arteries for surgical outcome. Eur J Cardiothorac Surg. 2018;54:149-56.

Key Words: germ cell cancer, metastases, retrocrural, metastasectomy 